\title{
SOBRE O PAPEL DOS SIGNOS EM ATIVIDADES DE MODELAGEM MATEMÁTICA
}

\author{
ON THE ROLE OF SIGNS IN MATHEMATICAL MODELLING ACTIVITIES \\ Michele Regiane Dias Veronez \\ Universidade Estadual do Paraná / michele.veronez@unespar.edu.br \\ Lourdes Maria Werle de Almeida \\ Universidade Estadual de Londrina/ lourdes@uel.br
}

\begin{abstract}
Resumo
Envolvidos com atividades de modelagem matemática os alunos têm oportunidade de utilizar e/ou produzir signos associados à situação, ao problema, aos objetos matemáticos e à resposta reconhecida como uma solução para o problema. A caracterização de signo é pautada na concepção de Charles Sanders Peirce - de que signo é algo que está no lugar de outra coisa - e, nas assertivas de Heinz Steinbring, de que o signo tem duas funções, uma função semiótica e uma função epistemológica. Com o propósito de investigar o papel dos signos nos encaminhamentos dados pelos alunos na busca por solução para o problema, apresentamos uma atividade de modelagem matemática, identificando os signos utilizados e/ou produzidos por eles. Como resultado inferimos que os signos, associados às suas funções semiótica e epistemológica, se complementam, indicando que além dos signos representarem algo que os alunos pretendem comunicar, sinalizam mobilização e/ou produção de conhecimento acerca do que o signo representa.
\end{abstract}

Palavras-chave: Modelagem Matemática. Semiótica. Funções dos signos.

\section{Abstract}

Involved with mathematical modelling activities students have the opportunity to use and/or produce signs which are connected to the situation, the problem, to mathematical objects and the result recognized as the solution for the problem. The characterization of the sign is guided on Charles Sanders Peirce's conception - the sign is something that is in place of something else - and on Heinz Steinbring's assertions of signs having two functions, a semiotic function and an epistemological function. In order to investigate the role of signs in the proceedings undertaken by the students in the search for solution to the problem, we present an mathematical modelling activity, identifying the signs use and/or produce by them. As a result we infer that the signs, associated with their semiotic and epistemological functions, complement each other, indicating that besides these signs represent something students want to communicate, they indicate mobilizations and/or production students' knowledge about what the sign represents.

Keywords: Mathematical Modelling. Semiotics. Functions of the signs. 


\section{Introdução}

A discussão teórica que demarca o percurso conceitual da pesquisa de doutoramento, da primeira autora, que possibilitou as reflexões sublinhadas neste trabalho ampara-se no reconhecimento de que os meios de relacionamento do homem com o mundo são permeados por redes de signos e que nas aulas de matemática há um uso diversificado de signos. Neste artigo, em particular, referimo-nos às aulas de matemática em que os alunos desenvolvem atividades de modelagem matemática.

Pautadas nas orientações da Semiótica - ciência dos signos - e alinhadas às ideias de Peirce (2012) - de que o signo é algo que está no lugar de outra coisa - e de Steinbring (2006), de que o signo tem duas funções, uma função semiótica - que consiste no potencial do signo para representar algo, e uma função epistemológica - que revela o conhecimento que o sujeito que utiliza e/ou produz o signo tem sobre o objeto representado (STEINBRING, 2005), temos como objetivo investigar os papéis dos signos no desenvolvimento de uma atividade de modelagem matemática realizado por alunos de um curso de Licenciatura em Matemática.

A partir do entendimento de que modelagem matemática é uma atividade associada à busca por uma solução para uma situação-problema e que "pode ser descrita em termos de uma situação inicial (problemática), de uma situação final desejada (que representa uma solução para a situação inicial) e de um conjunto de procedimentos e conceitos necessários para passar da situação inicial para a final" (ALMEIDA, 2010, p.399), nossa atenção se direciona para os signos utilizados e/ou produzidos pelos alunos ao transitarem da situação inicial para a final.

Sendo assim, apresentamos e discutimos uma atividade de modelagem matemática, identificando os signos utilizados e/ou produzidos pelos alunos que a desenvolveram, bem como os papéis desses signos nos encaminhamentos dados por eles na busca por solução para o problema em questão. Para a análise das relações entre os papéis desempenhados por esses signos e os encaminhamentos assumidos pelos alunos, atentamo-nos para as funções semiótica e epistemológica de tais signos.

\section{Modelagem Matemática e Interlocuções com a Semiótica}

Levando em consideração a caracterização de modelagem matemática a que já nos referimos, tem-se que o ponto de partida de uma atividade de modelagem matemática é uma situação-problema e que a busca por uma solução para essa situação surge como uma possibilidade de os alunos utilizarem e/ou produzirem signos.

O desenvolvimento de uma atividade de modelagem matemática requer dos alunos processos investigativos e interpretativos a partir de conceitos matemáticos e de conhecimentos acerca da situação em estudo e é nesses processos que signos são por eles manifestados. Seja de forma implícita (por meio de procedimentos) ou explícita (por meio de representações, de modo geral, simbólicas), esses signos retratam as intenções 
e conhecimentos dos alunos nas escolhas que fazem ao longo da atividade de modelagem matemática.

O fato de que os encaminhamentos em uma atividade de modelagem matemática, sejam do professor, sejam dos alunos, são amparados nos conhecimentos mobilizados por eles acerca da situação em estudo e dos objetos matemáticos que utilizam na tentativa de encontrar uma solução para o problema advindo dessa situação, os signos, utilizados e/ou produzidos pelos alunos, têm relação, ora com a situação, ora com o problema em estudo, ora com os objetos matemáticos e ora com a resposta reconhecida como uma solução para o problema. Ou seja, os signos se configuram como meios pelos quais os alunos manifestam seus pensamentos e conhecimentos enquanto buscam encontrar uma solução para o problema advindo da situação em foco.

Diversos são os trabalhos que trazem à tona aspectos sobre os signos em atividades de modelagem matemática. Dentre eles, citamos os realizados por Kehle e Cunningham (2000), Carreira (2001), Kehle e Lester (2003), Williams e Wake (2007), Silva (2008), Almeida (2010), Almeida, Silva e Vertuan (2011), Almeida e Silva (2012), Silva (2013), Veronez (2013) e Silva e Veronez (2014).

Kehle e Cunningham (2000), a fim de analisar o comportamento dos alunos em atividades de modelagem matemática relacionaram os tipos de raciocínio ${ }^{1}$ com as diferentes etapas de uma atividade de modelagem matemática, concluindo que as etapas requerem atividades cognitivas em vários modos de inferência. Esses diferentes tipos de raciocínio, associados às diferentes ações cognitivas dos alunos em atividades de modelagem matemática, também conduzem as discussões de Almeida e Silva (2012).

Silva (2008), a partir de uma análise documental de atividades de modelagem matemática existentes na literatura, estabelece algumas relações entre a categorização dos signos $^{2}$ estabelecida por Peirce, os modos de inferência - abdução, indução e dedução - e os fenômenos de congruência e não-congruência das conversões entre registros apresentados em atividades de modelagem matemática. Já Kehle e Lester (2003), associam os modos de inferência - abdução, indução e dedução - às categorias fenomenológicas $^{3}$ no desenvolvimento de atividades de modelagem para analisarem 0 comportamento dos alunos ao longo dessas atividades. Aproximações entre as categorizações fenomenológicas, os níveis de relações entre os signos estabelecidos por Peirce e a Modelagem Matemática são abordadas em Almeida, Silva e Vertuan (2011).

Focalizando o problema e o objeto matemático em atividades de modelagem matemática, Silva (2013), discute sobre os signos, produzidos pelos alunos, atrelados a esses objetos (problema e objeto matemático). Em sua análise revela a ocorrência de atribuição de significado tanto para o problema quanto para o objeto matemático por parte

\footnotetext{
${ }^{1}$ Esses tipos de raciocínio dizem respeito aos modos de inferência - abdução, indução e dedução - na categorização dos signos estabelecida por Peirce (2012).

${ }^{2} \mathrm{Na}$ semiótica peirceana um signo pode ser ícone, índice e símbolo.

${ }^{3}$ As categorias fenomenológicas dizem respeito a três elementos formais e universais em todos os fenômenos que se apresentam à percepção e à mente. Peirce denotou essas categorias por qualidade, reação e mediação, no entanto, para fins científicos, ele preferiu, posteriormente, utilizar as terminologias Primeiridade, Secundidade e Terceiridade para se referir às categorias fenomenológicas.
} 
dos alunos e que tal atribuição se intensifica com a familiarização dos alunos com atividades dessa natureza. Em Silva e Veronez (2014), os autores evidenciam os signos que viabilizam que os alunos, gradativamente, atribuíssem significado para o problema e para o objeto matemático em uma atividade de modelagem matemática.

De forma geral, esses trabalhos asseguram que em atividades de modelagem matemática diversos são os signos utilizados e/ou produzidos por aqueles que a desenvolvem enquanto transitam da situação inicial para a final e que tais signos, além de retratar intenções, revelam conhecimentos acerca da matemática e da situação. Neste trabalho, o olhar para os signos considera esses aspectos, pautado em suas funções: semiótica e epistemológica.

\section{As funções semiótica e epistemológica dos signos}

Peirce (1972) caracteriza o signo a partir de três elementos: o representamen (ou fundamento do signo), o objeto e o interpretante.

Um signo, ou representamen é algo que, sob certo aspecto ou algum modo, representa alguma coisa para alguém. Dirige-se a alguém, isto é, cria na mente dessa pessoa um signo equivalente ou talvez um signo melhor desenvolvido. Ao signo, assim criado, denomino interpretante do primeiro signo. O signo representa alguma coisa, seu objeto. Coloca-se no lugar desse objeto, não sob todos os aspectos, mas com referência a um tipo de ideia que tenho, por vezes, denominado o fundamento do signo (PEIRCE, 1972, p. 94, grifos do autor).

Considerando o que Peirce (2012) denota por representar, o signo não possui capacidade de substituir o objeto, mas de estar no lugar dele e, da relação entre signo e objeto resulta outro signo, o interpretante. No entanto, o interpretante é um signo que, para Santaella (2007, p. 23), corresponde ao "efeito interpretativo que o signo produz em uma mente".

Cada signo, na mente do intérprete, gera um interpretante que, por sua vez, funciona como representamen de um novo signo; "a ação de gerar, cedo ou tarde, interpretantes efetivos é própria do signo" (SANTAELLA, 2012, p.9). Isso faz com que esse processo de geração de interpretantes e, portanto, de signos, seja um processo dinâmico na mente do intérprete. Segundo Santaella (2012, p.18), "faz parte da natureza do próprio signo que ele tenha o poder de gerar um interpretante, e assim por diante". A Figura 1 ilustra esse processo de geração de interpretantes, em um contexto de trama ${ }^{4}$.

\footnotetext{
${ }^{4}$ Seeger (2004) associa o processo de geração de interpretantes a uma trama no sentido de que esse processo é constituído a partir de redes entre cada um dos elementos que compõem a tríade semiótica.
} 


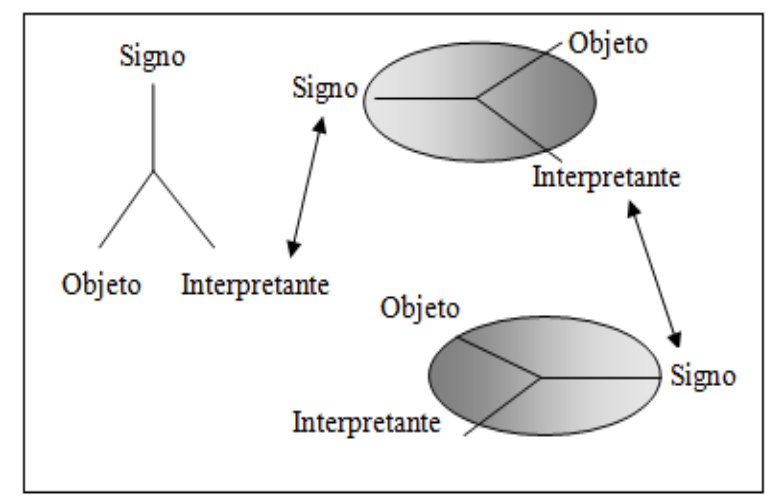

Figura 1 - Trama semiótica

Fonte: Adaptado de Seeger (2004, p. 211, Tradução nossa).

A trama semiótica, conforme proposta por Seeger (2004), sugere que o processo de geração de signos seja estendido para o infinito. A esse processo ad infinitum Peirce caracterizou como semiose (PEIRCE, 2012). Na palavra semiose, o sufixo ose, derivado do grego significa ação, e o prefixo semi, relativo à semion, denota signo, então semiose é a ação do signo. Ou seja, a semiose é uma ação que envolve a cooperação entre os três elementos da tríade: o signo, seu objeto e seu interpretante; é o "processo no qual o signo tem um efeito cognitivo sobre o intérprete" (NÖTH, 2008, p. 66).

Algo importante aparece quando a tríade semiótica é compreendida em um contexto de trama, pois o signo que representa o objeto, no sentido assumido por Peirce, gera o signo produzido pelo intérprete - o interpretante, que por sua vez, pode se comportar como um signo que evoca outro objeto, que modifica o interpretante anterior. Esse processo de geração de signos - semiose - é um processo característico da capacidade humana. É o sujeito o ser capaz de produzir entendimentos a partir de signos das mais diversas naturezas e da mediação entre eles. Nesse sentido, o signo existe somente se puder representar algo diferente dele, pois o signo não é o objeto, ele está no lugar do objeto (SANTAELLA, 2012). Os signos, portanto, se referem a um certo referente ou a um certo contexto que representa algo que se quer comunicar ou representar. No âmbito da matemática, por exemplo, a figura de um triângulo (que se comporta como um signo) refere-se ao objeto triângulo.

A partir do entendimento de que é impossível compreender e operar diretamente os objetos, sobretudo os objetos matemáticos, sem recorrência aos signos, assume-se, de acordo com as ideias de Hoffmann (2006), que os signos são, por um lado, meios para pensar sobre objetos e relações matemáticas e, por outro, produtos de tais pensamentos. Assim, em um esforço de olhar para os signos na busca por elucidar possíveis relações entre signos e objetos, ou como coloca Steinbring (2005), entre signos e contexto de referência, consideramos, conforme sugerido por Steinbring (2006), duas funções dos signos: a função semiótica e a função epistemológica.

A função semiótica expressa uma relação referencial entre objeto/contexto de referência e signo, e consiste no potencial do signo para representar o objeto, ou seja, para estar no lugar dele. Essa função diz respeito à capacidade que o sujeito tem de gerar imagens mentais de objetos ou ações, e por meio delas chegar ao signo (da ação ou do objeto) (STEINBRING, 2006). Sendo assim, não há, portanto, função semiótica sem a presença simultânea desses dois elementos: objeto/contexto de referência e signo. A função epistemológica, por sua vez, revela o conhecimento que o sujeito que utiliza e/ou produz o signo tem sobre o objeto/contexto de referência representado (STEINBRING, 2005). Nessa função um aspecto a considerar é o contexto no qual o signo emerge, pois esse contexto determina as condições nas quais se estabelecem as relações entre objeto/contexto de referência e signo. Otte (2001) explica que a epistemologia está na 
relação entre objeto e signo e que é por meio da epistemologia que as características dos objetos podem ser observadas nos signos que os referenciam.

Steinbring (2009) encaminha uma discussão em torno da relação entre objeto/contexto de referência e signo na tentativa de esclarecer como se processa essa questão de interdependência e reciprocidade entre esses dois elementos. Nessa obra o autor enfatiza que signos e objetos se relacionam de forma a compor um intercâmbio comunicativo entre sujeito e funcionamento cognitivo, gerando formas de pensamento. Essas formas estão associadas aos signos mobilizados pelos alunos acerca do objeto e atrelados à função semiótica dos signos. Porém, quando os signos não somente referemse ao objeto, mas carregam consigo conhecimentos que o sujeito tem sobre aquilo que 0 signo representa, têm-se a função epistemológica (STEINBRING, 2009). A Figura 2 ilustra as características das funções semiótica e epistemológica dos signos.

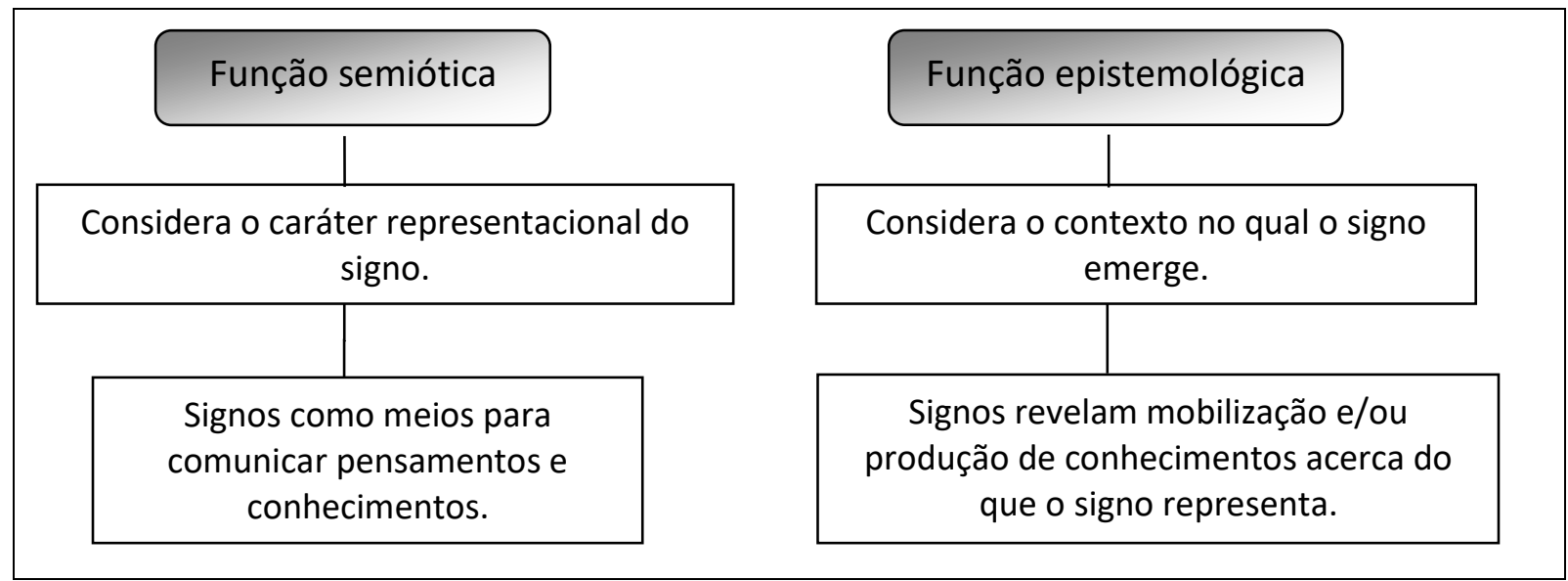

Figura 2 - As funções dos signos

Fonte: Adaptado de Veronez (2013, p.148).

$\mathrm{Na}$ relação entre objetos/contextos de referência e signos que os referenciam, os signos estabelecem elos entre as dimensões epistemológica e comunicativa dos processos de geração de pensamentos e de comunicação de conhecimentos que permeiam as atitudes dos alunos nas atividades que eles desenvolvem. Isso porque os signos medeiam as relações entre indivíduo, seu contexto e objeto em estudo. Segundo Steinbring (2002), à dimensão epistemológica desses processos associa-se a função epistemológica dos signos e a função semiótica deles está relacionada à dimensão comunicativa de tais processos.

\section{Signos em uma atividade de modelagem matemática}

O valor referente ao Instituto Nacional do Seguro Social - INSS, descontado na folha de pagamento, foi o que levou um grupo de alunos ${ }^{5}$, no âmbito da disciplina de Introdução à Modelagem Matemática de um curso de Licenciatura em Matemática, a desenvolver a atividade "Poupando a futura aposentadoria", apresentada nesta seção. Para a coleta dos dados que orientaram as análises aqui descritas foram utilizados registros escritos (relatórios de aula e versão final ${ }^{6}$ da atividade de modelagem matemática desenvolvida) e falados (que correspondem às transcrições das gravações em áudio das aulas e entrevista) dos alunos.

${ }^{5}$ Esse grupo era formado por três alunos.

${ }^{6}$ Foi denominada, pelos alunos, de trabalho de modelagem. 
Juntamente com a definição do tema para estudo os alunos elencaram um problema a resolver: "Será que se nós não contribuíssemos com o INSS e aplicássemos esse valor em uma poupança, conseguiríamos viver bem ou pelo menos sobreviver com esse dinheiro quando não pudéssemos mais trabalhar?"

A partir dessa pergunta, o propósito dos alunos para com a atividade ficou aparentemente definido e foi sendo delineado com base na declaração: "A gente poderia ver então, qual é a base de cálculo que eles usam para descontar o imposto do salário do trabalhador." Tal declaração, bem como a informação de que a contribuição ao INSS é dada segundo faixas salariais, denunciam que houve envolvimento dos alunos para com o tema, tanto que eles reestruturam o problema inicial, reformulando-o da seguinte forma: "Depositar mensalmente $8 \%$ do valor do salário mínimo em uma poupança, por um período de 35 anos, possibilitará à pessoa que ganha esse salário uma aposentadoria tranquila?"

Nesse envolvimento inicial dos alunos com a atividade de modelagem matemática, o problema proposto pelos alunos torna-se o objeto de estudo. Assim, tanto a declaração enunciada como as informações coletadas, referentes às taxas de desconto do salário segundo as faixas salariais e ao tempo de contribuição, correspondem a signos associados ao contexto de referência tema em estudo. Nesse caso, esses signos, além de terem uma relação referencial com o tema, e isso diz respeito à sua função semiótica, agregam também as interpretações dos alunos sobre o que é importante considerar nesse momento da atividade. Tais signos têm, portanto, a contribuição ao INSS, ou seja, o desconto na folha de pagamento do trabalhador como contexto de referência.

Dentre as informações coletadas, maior atenção é dada pelos alunos às taxas relativas à contribuição ao INSS e, nesse encaminhamento, também reafirmam aspectos considerados no problema, como o tempo de contribuição do trabalhador e a taxa de desconto do salário.

O engajamento dos alunos com a atividade ocorre a partir de duas sugestões de um dos alunos do grupo. A primeira (" $E$ se a gente seguisse um padrão... que é sempre $8 \%$ que vai ser descontado"), embora seja um signo que se refere a uma delimitação das informações relativa ao valor de contribuição ao INSS, é algo que parece ser consenso no grupo e, portanto, não leva à produção de outros signos vinculados diretamente a esse. Já a segunda ("A gente tem meio que analisar os aumentos dos salários anteriores pra gente ver como ele está aumentando ano a ano"), corresponde a um signo que sugere que os alunos encontrem informações sobre os salários mínimos nos últimos anos (Tabela 1) e como têm se comportado seus aumentos. O papel desempenhado por esses signos é indicado pelas suas funções (semiótica e epistemológica), uma vez que é relevante o caráter representacional do signo bem como o contexto no qual emergiram.

Tabela 1 - Salários mínimos - 2000 a 2012

\begin{tabular}{c|c|c|c|c|c}
\hline Vigência & $\begin{array}{c}\text { Valor } \\
(\mathrm{R} \$)\end{array}$ & Vigência & $\begin{array}{c}\text { Valor } \\
(\mathrm{R} \$)\end{array}$ & $\begin{array}{c}\text { Vigência } \\
\text { Valor } \\
(\mathrm{R} \$)\end{array}$ \\
\hline $03 / 04 / 2000$ & 151,00 & $01 / 05 / 2005$ & 300,00 & $01 / 01 / 2010$ & 510,00 \\
\hline $01 / 04 / 2001$ & 180,00 & $01 / 04 / 2006$ & 350,00 & $01 / 03 / 2011$ & 545,00 \\
\hline $01 / 04 / 2002$ & 200,00 & $01 / 04 / 2007$ & 380,00 & $01 / 01 / 2012$ & 622,00 \\
\hline $01 / 04 / 2003$ & 240,00 & $01 / 03 / 2008$ & 415,00 & & \\
\hline $01 / 05 / 2004$ & 260,00 & $01 / 02 / 2009$ & 465,00 & & \\
\hline
\end{tabular}

Fonte: www.guiatrabalhista.com.br/guia/salario minimo.htm

De posse das informações da Tabela 1, signo utilizado pelos alunos para pensar acerca dos aumentos do salário mínimo desde o ano 2000, eles produzem a terceira e quarta colunas da Tabela 2, que indica as estratégias deles para encontrar uma taxa que represente o aumento salarial. Além disso, a Tabela 2 retrata a intenção dos alunos de 
calcular o total depositado por uma pessoa, nas condições que eles estabeleceram no problema.

Tabela 2 - Aumentos do salário mínimo no período de 2000 a 2012

\begin{tabular}{c|c|c|c}
\hline Vigência & Valor $(\mathrm{R} \$)$ & $\begin{array}{c}\text { Aumento em } \\
\text { relação ao ano } \\
\text { anterior }(\mathrm{R} \$)\end{array}$ & $\begin{array}{c}\text { Aumento em } \\
\text { relação ao ano } \\
\text { anterior }(\%)\end{array}$ \\
\hline $03 / 04 / 2000$ & 151,00 & & 19,21 \\
\hline $01 / 04 / 2001$ & 180,00 & 29,00 & 11,11 \\
\hline $01 / 04 / 2002$ & 200,00 & 20,00 & 20,00 \\
\hline $01 / 04 / 2003$ & 240,00 & 40,00 & 8,33 \\
\hline $01 / 05 / 2004$ & 260,00 & 20,00 & 15,38 \\
\hline $01 / 05 / 2005$ & 300,00 & 40,00 & 16,67 \\
\hline $01 / 04 / 2006$ & 350,00 & 50,00 & 8,57 \\
\hline $01 / 04 / 2007$ & 380,00 & 30,00 & 9,21 \\
\hline $01 / 03 / 2008$ & 415,00 & 35,00 & 12,05 \\
\hline $01 / 02 / 2009$ & 465,00 & 50,00 & 9,68 \\
\hline $01 / 01 / 2010$ & 510,00 & 45,00 & 6,86 \\
\hline $01 / 03 / 2011$ & 545,00 & 35,00 & 14,13 \\
\hline $01 / 01 / 2012$ & 622,00 & 77,00 & \\
\hline
\end{tabular}

Fonte: Trabalho de modelagem entregue pelo grupo.

Os aumentos do salário mínimo a cada ano, apresentados na Tabela 2, assim como a taxa anual dos aumentos, correspondem a signos que sugerem que os alunos pensem em estratégias para encontrar a taxa de aumento salarial e estão atrelados também ao contexto de referência tema em estudo. Tais signos denotam que os alunos reconhecem o que precisam para avançar no desenvolvimento da atividade e, nesse sentido, carregam interpretações dos alunos, reforçando a função epistemológica desses signos.

Como nessa atividade de modelagem matemática os alunos já partiram de uma pergunta, eles também tinham ideias de como avançar na investigação do problema. Sendo assim, eles decidem considerar um valor representativo desses aumentos a cada ano, a partir da declaração: "Ah... vamos fazer a média disso", enunciada por um dos alunos do grupo. Assumido esse encaminhamento os alunos analisam suas escolhas a partir da representação matemática que retrata o valor do salário mínimo a cada ano (Figura 3), com base no histórico desses aumentos.

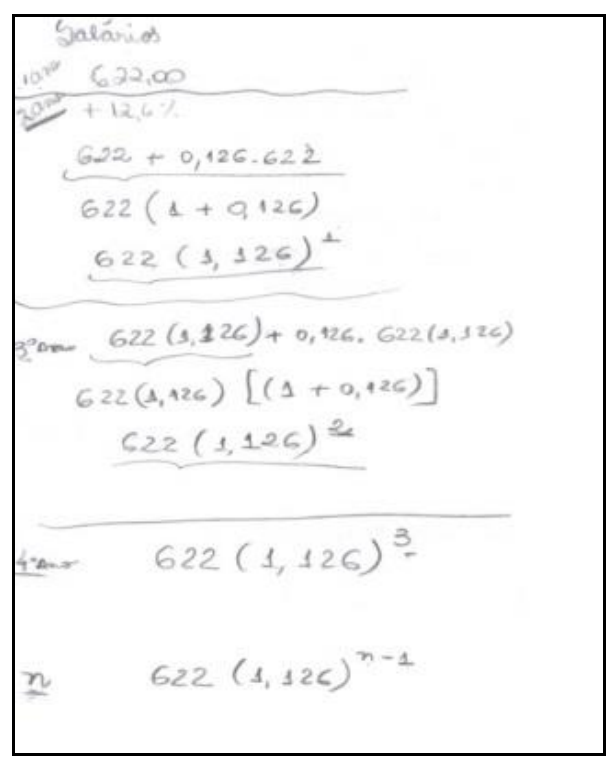

Figura 3 - Primeira estratégia dos alunos para obtenção da taxa dos aumentos do salário mínimo Fonte: Relatório 2 entregue pelo grupo. 
A sugestão de calcular a média não foi aceita por todos os integrantes do grupo, porém é assumida por eles devido à fragilidade da argumentação de outro aluno do grupo - "Sei não. Uma vez um professor me disse, eu estou lembrando disso agora, que não vale muito fazer a média quando os valores são muito discrepantes. Acho que foi esse termo que ele usou. E nesses valores acho que acontece isso". A sugestão inicial então, configura-se como um signo que indica uma estratégia a seguir. Contudo, a declaração "Nossa, mas esse salário tá muito alto. Pode o salário mínimo subir mil reais por ano?" após ter calculado o salário mínimo no ano trinta e cinco a partir da representação algébrica apresentada na Figura 3, sugere reflexão acerca da estratégia de usar a média dos aumentos para estimar o valor do salário mínimo a cada ano.

O argumento usado por esse aluno de perguntar se é possível o salário mínimo aumentar mil reais por ano é considerado 'forte' pelos demais alunos do grupo; tanto que o grupo retoma a discussão sobre a taxa de aumento do salário mínimo. Parece-nos possível inferir que tal declaração corresponde a um signo relativo ao contexto de referência tema em estudo, que desempenha o papel de provocar que decisões tomadas sejam revistas e que leva os alunos a reconhecer que ter usado a taxa de $12,6 \%$ para o aumento do salário não foi o mais adequado. Esse é um indício da função epistemológica desse signo.

Todavia, foi a informação - "Se o salário mesmo, que eu ouvi falar, for para seiscentos e setenta e cinco reais, daí vai ter mais um valor oito ponto alguma coisa, oito ponto cinco dois" - a decisiva nesse processo de rever uma decisão tomada. Essa informação também constitui um signo associado ao contexto de referência em estudo, revelando sua função epistemológica. Tal signo impacta o procedimento anteriormente adotado, de fazer a média dos aumentos do salário mínimo, e provoca os alunos a pensar em outra estratégia para encontrar a taxa de tais aumentos.

Além disso, dessa declaração emerge outro signo ("Vamos pegar esses valores de oito e alguma coisa e fazer a média entre eles"), com o tema de estudo sendo o contexto de referência, que conduz os alunos a determinar a taxa de aumento do salário mínimo, como sendo $8,45 \%$, a partir do cálculo do seu valor no ano trinta e cinco usando a expressão $S_{n}=622(0,0845)^{n-1}$. A afirmação - "Isso vai dar um salário de nove mil e pouco... daqui a trinta e cinco anos. Agora sim. Parece mais razoável isso" - retrata esse fato, revela a função epistemológica do signo e ratifica esse novo procedimento adotado pelo grupo (Figura 4).

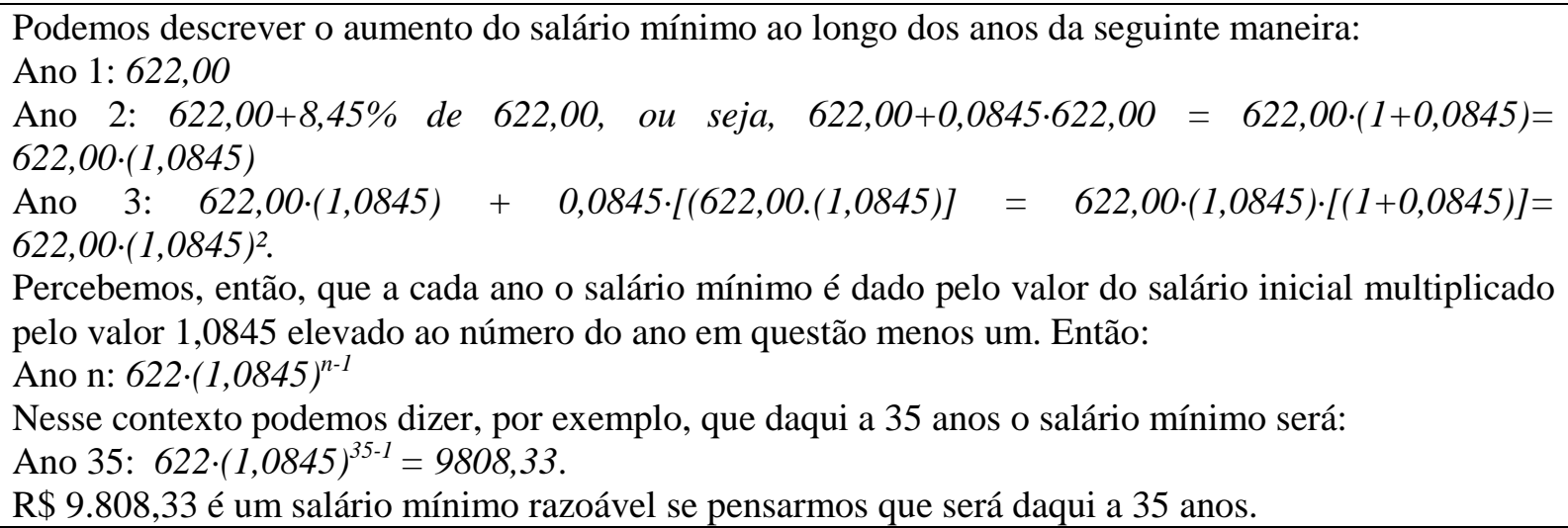

Figura 4 - Sobre o aumento do salário mínimo ao longo dos anos Fonte: Trabalho de modelagem entregue pelo grupo.

Para a produção dos signos, atrelados ao contexto de referência em estudo, evidenciados até esse momento do desenvolvimento da atividade, os alunos mobilizam 
seus conhecimentos matemáticos relativos à média e à moda e utilizam-se de meios diversos para comunicá-los. Nesses signos, fica subjacente tanto o seu caráter representacional, função semiótica do signo, como o fato de carregarem consigo os conhecimentos dos alunos sobre o que esses signos representam, característica da função epistemológica do signo.

Determinada a taxa relativa ao aumento do salário mínimo, os alunos fazem algumas suposições (Quadro 1) que contribuem para encaminhamentos futuros a serem assumidos ao longo da atividade. É também a essas suposições que os alunos recorrem quando, por algum motivo, sentem necessidade de reconsiderar alguns aspectos ou considerar outros, inicialmente não usados.

\section{Quadro 1 - Suposições realizadas pelos alunos}

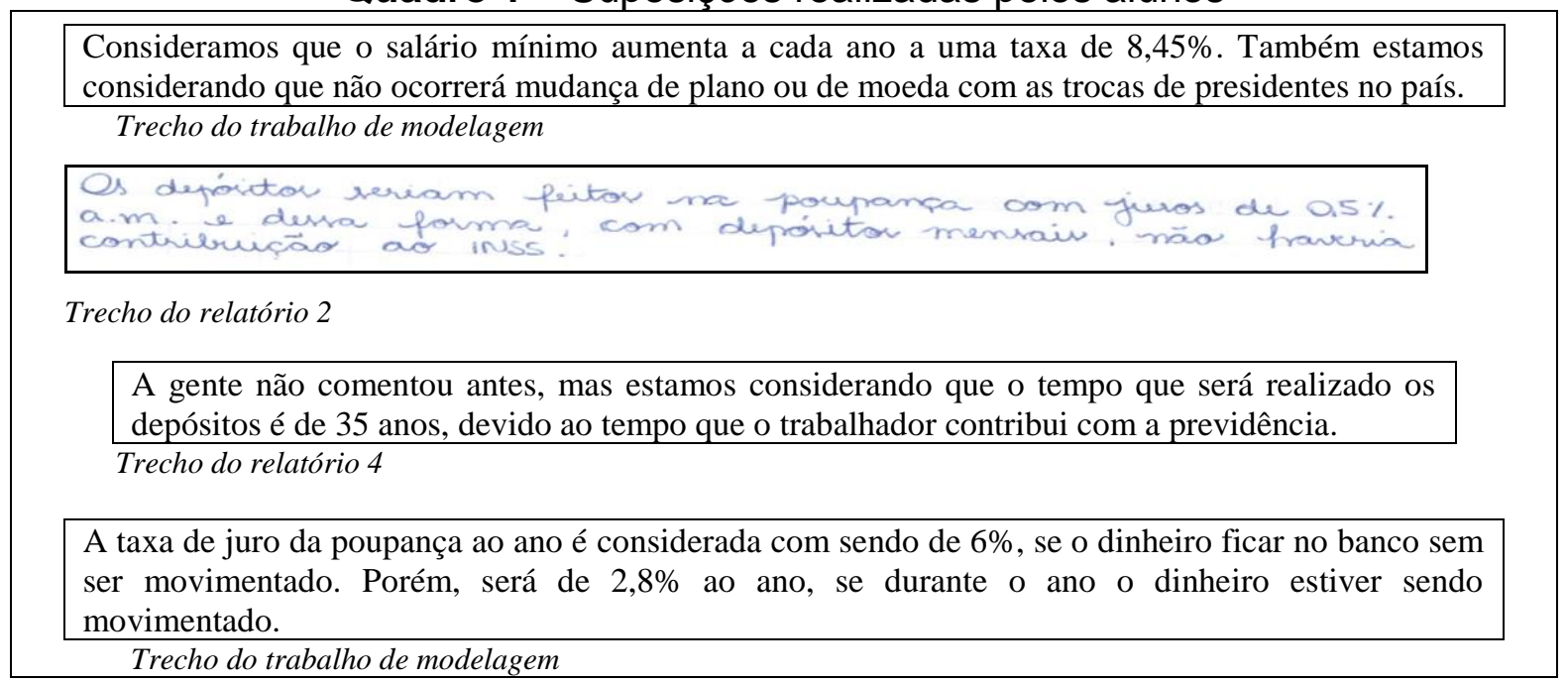

Fonte: Veronez (2013).

Essas suposições se configuram como signos que resultaram de interpretações dos alunos acerca das informações sobre o tema em questão (contexto de referência) e indicam sua função epistemológica. Nesse sentido, retratam alguns conhecimentos matemáticos mobilizados por eles (sobre média, moda, porcentagem) e conhecimentos sobre a situação (sobre o INSS, poupança, taxas de juros, entre outros) que circundam o problema por eles evidenciado.

A partir da definição da taxa de aumento do salário mínimo (adotaram a taxa como sendo $8,45 \%$ ) os alunos investem na busca por uma representação que associa os depósitos em relação à quantia depositada na poupança, mês a mês, ao longo de trinta e cinco anos e, obtêm a expressão $\left[p x+p x(1,0845)+p x(1,0845)^{2}+\cdots+p x(1,0845)^{n-1}\right] \cdot 12$ que sinaliza que os alunos representaram a soma dos depósitos mensais de forma genérica e, de certa forma, ampliam o contexto contemplado no problema que eles buscavam solucionar.

Tal expressão constitui um signo que viabiliza aos alunos uma análise da formulação inicial do problema, sendo essa análise um indicativo das funções semiótica e epistemológica desse signo. A função semiótica pode ser evidenciada a partir do caráter representacional do signo; a expressão representa algo, ou seja, representa o valor acumulado pelos depósitos mensais de $8,45 \%$ do salário mínimo durante trinta e cinco anos. Entretanto, nessa expressão também estão implícitos os conhecimentos que os alunos têm sobre o que esse signo representa, ou seja, a qual objeto está relacionado, a saber, o problema em estudo. Isso sinaliza a função epistemológica desse signo. 
Interessados em saber qual o valor, referente aos depósitos, acumulado ao longo dos trinta e cinco anos os alunos associam a soma dos depósitos à soma de uma progressão geométrica. A Figura 5 ilustra o procedimento dos alunos no que concerne ao cálculo do valor do depósito acumulado nos trinta e cinco anos, sem considerar os juros da poupança. É em decorrência desse procedimento, no qual assumem que o depósito mês a mês se comporta segundo uma progressão geométrica, que os alunos calcularam o valor que seria depositado ao longo desses anos.

A sequência $\left(p x, p x(1,0845), p x(1,0845)^{2}, \ldots, p x(1,0845)^{n-1}\right)$ é uma Progressão Geométrica Finita de razão $q=1,0845$ e primeiro termo $a_{l}=p x$.

Logo, fazendo a soma dos termos da PG, temos:

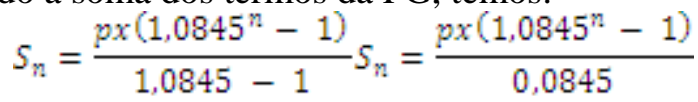

Assumindo $p=0,08, x=622,00$ e $n=35$ :

$$
\begin{aligned}
& S_{25}=\frac{0,00.622\left[1,0845^{35}-1\right)}{0,0845} S_{25}=\frac{49,76[16,1015)}{0,0845}=9.481,7827 \\
& S_{75} \times 12=9481,7827 \cdot 12=113.781,39
\end{aligned}
$$

Descobrimos, então, que o montante depositado ao final de 35 anos é de $\mathrm{R} \$ 113.781,39$.

Figura 5 - Sobre o valor acumulado pelos depósitos realizados, mês a mês, por 35 anos Fonte: Trabalho de modelagem entregue pelo grupo.

Somente depois que os alunos encontraram o valor acumulado por trinta e cinco anos de depósitos mensais de $8 \%$ do salário mínimo é que eles reconheceram que 0 problema não fora solucionado. Tampouco, que esse procedimento os levaria a sua solução. Nesse sentido, a Figura 5 se revela como determinante para os alunos reconhecerem que essa não era a melhor opção de encaminhamento para a atividade e, portanto, o que eles deveriam fazer era considerar os depósitos já embutindo os juros. Então, a Figura 5 corresponde a um signo relativo ao contexto de referência problema em estudo, que sinaliza que outro encaminhamento deve ser assumido para que seja possível responder ao problema por eles proposto. Logo, fica evidenciada a função epistemológica desse signo, já que nele é considerado o contexto no qual emergiu.

Buscando meios para responder ao problema e considerando a simulação da Figura 6, os alunos procuram por uma representação matemática que retrate além dos depósitos efetuados mês a mês, os juros contabilizados sobre esses depósitos (Figura 7). A Figura 6 é um signo associado ao contexto de referência problema em estudo, que revela a intenção dos alunos de encontrar uma representação matemática para 0 problema. Tal intenção é decorrente da função epistemológica desse signo.

No primeiro mês temos os $8 \%$ do salário mínimo depositado na conta. Por exemplo, se fosse o salário desse ano o depósito de todo mês seria de quarenta e nove reais e pouquinho. No segundo mês nós teríamos o juro do valor que estava na conta no mês anterior mais o valor que estava na conta no mês anterior mais o depósito desse mês. No terceiro mês a gente tem o valor anterior vezes a taxa de juro, mais o valor do mês anterior, mais o depósito dos $8 \%$ do salário. Vamos fazer... acho que até o $6^{\circ}$ mês para ver o que acontece.

Figura 6 - Simulação realizada pelos alunos

Fonte: Relatório 4 entregue pelo grupo. 


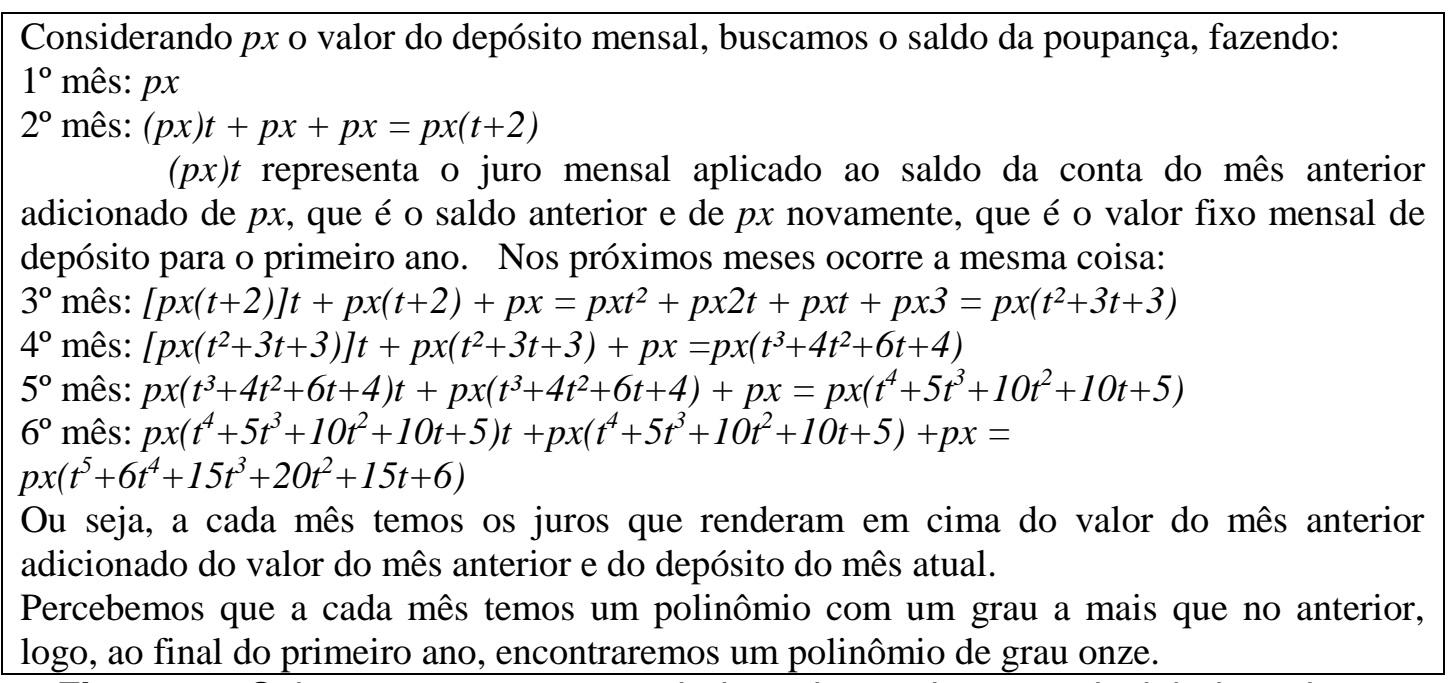

Figura 7 - Sobre o montante acumulado ao longo dos anos, incluindo os juros Fonte: Trabalho de modelagem entregue pelo grupo.

O encaminhamento assumido pelos alunos (Figura 7), que no âmbito da modelagem matemática refere-se à construção de um modelo matemático para a situação é um signo, associado ao contexto de referência problema em estudo, que retrata o trânsito da situação inicial para uma situação final. Nesse signo os alunos não deixam explícito o valor do salário assumido e a taxa de desconto. Inferimos, portanto, que eles têm a intenção de apresentar um modelo matemático que contemple outros salários e, consequentemente, outras faixas de desconto. Tal atitude dos alunos revelam as funções semiótica e epistemológica desse signo, pois ao mesmo tempo em que esse signo representa algo que se quer representar, ele sinaliza intenções dos alunos sobre o que pretendem representar.

A partir do modelo matemático e da observação - "Olha o que tá acontecendo aqui!" (trabalhando apenas com os coeficientes dos polinômios) -, além de provocar os demais alunos do grupo a se atentar para aquilo que ele tinha descoberto, os direciona a pensar em um objeto matemático (triângulo de Pascal) com vista a encontrar uma generalização dos coeficientes dos polinômios. Podemos inferir que tal observação é um signo que contribui para a produção de outro signo (Quadro 2).

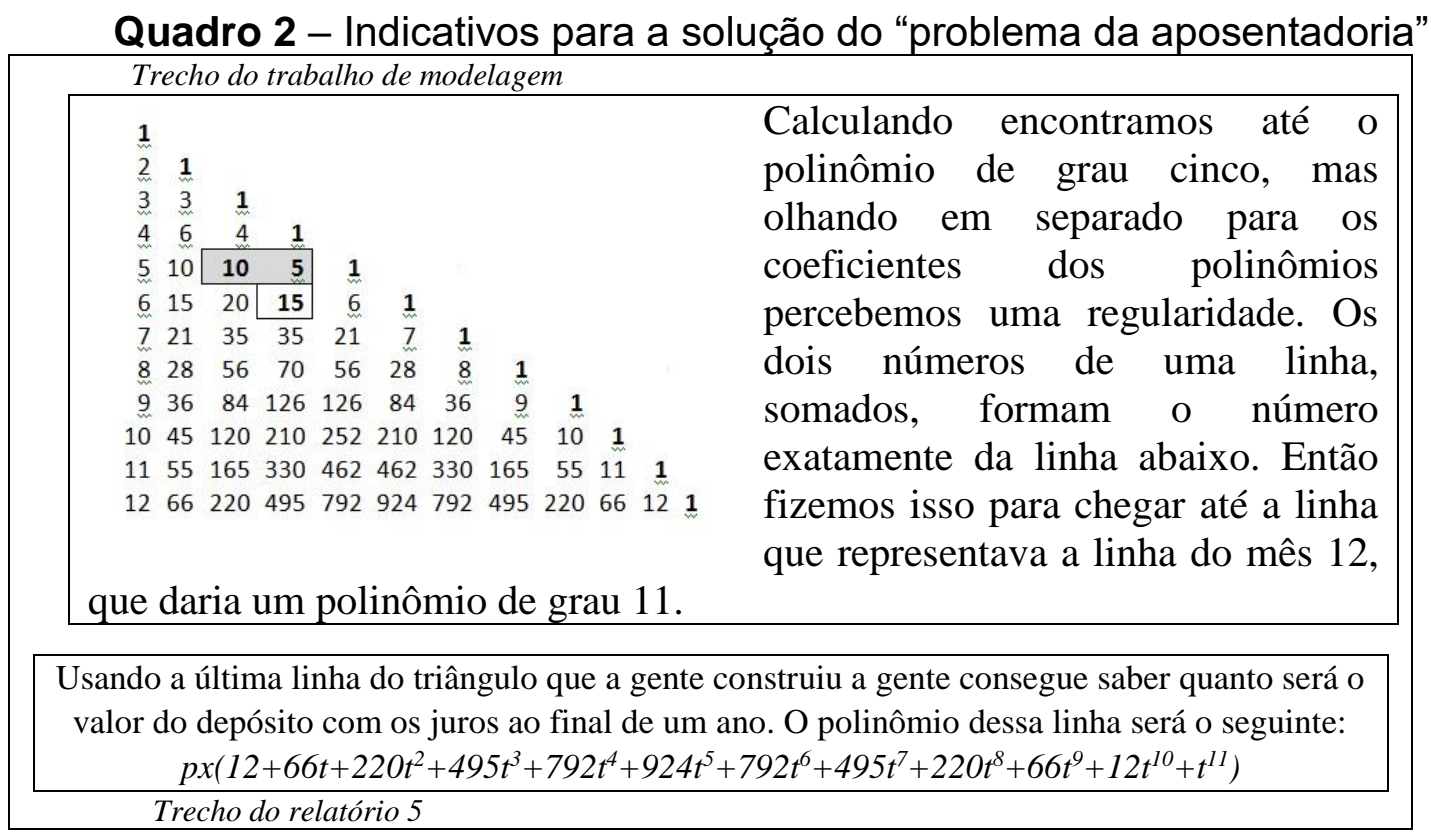


Se conseguíssemos colocar, ao invés de 12 meses, linhas referentes à 35 anos, ou seja, 420

linhas, a última linha nos daria um polinômio de grau 419, que nos daria o valor acumulado

na poupança, após 35 anos, que é o que queremos saber.

Trecho do relatório 5

\section{Fonte: Veronez (2013).}

As conclusões dos alunos apresentadas no Quadro 2 retratam suas intenções na tentativa de resolver o problema e, nesse sentido, se constitui em um signo atrelado ao contexto de referência objetos matemáticos relacionados ao problema. Esse signo carrega interpretações dos alunos (função epistemológica do signo) concernentes à generalização matemática que eles fazem com foco na situação em estudo e indica um encaminhamento que pode levar à solução do problema.

Muito embora os alunos tenham delineado uma solução para o problema, que aparece expressa na declaração - "Na linha 12 a gente vai ter o valor dos depósitos com os juros, em um ano. Agora como a gente vai calcular isso para 35 anos? Para isso a gente teria que construir um triângulo com... 420 linhas!" -, a sugestão de outro aluno do grupo - "Vamos tentar de outra forma". - é decisiva para os alunos assumirem outro encaminhamento para resolver o problema por eles proposto. Sendo assim, ambas as declarações correspondem a signos, relativos ao contexto de referência objetos matemáticos relacionados ao problema, que levam os alunos a repensar a resolução do problema. A primeira indica um meio para encontrar uma solução para o problema a partir do encaminhamento que o grupo tinha assumido. Por outro lado, a segunda convida os demais alunos a abandonar esse encaminhamento e a assumir outro. Em ambas há indicativos da função epistemológica desses signos.

Uma planilha com os cálculos dos valores depositados com os juros, durante 35 anos, reconhecida como um modelo matemático para a situação é um signo resultante de interpretações realizadas pelos alunos e que os conduziu a elaborar uma resposta para o problema (Figura 8).

Pegando o valor do montante acumulado e dividindo pelo salário no ano 36 , que seria de R\$ $10.637,14$, a gente vê que o trabalhador conseguirá se manter apenas por 22 meses. Portanto, a gente acredita, ao contrário do que a gente acreditava antes de se envolver com essa atividade de modelagem, que o ideal é continuar contribuindo com a Previdência Social.

\section{Figura 8 - Resposta para o problema apresentada pelos alunos}

Fonte: Relatório 5 entregue pelo grupo.

Essa resposta, além de corresponder a uma solução para o problema, corresponde a um signo, associado ao contexto de referência solução para o problema, que carrega aspectos epistemológicos dos conhecimentos dos alunos acerca da situação e do problema em si, confrontando, inclusive suas conjecturas iniciais denunciadas por um dos alunos do grupo - "Eu sempre pensei que não valia a pena contribuir... agora tenho certeza que vale".

Embora considerem terem respondido ao problema, no momento da socialização, os alunos comentam sobre as limitações desse problema, enfatizando que "na prática a gente sabe que não é possível deixar de contribuir com o INSS, então o nosso problema é algo que nós criamos, mas agora pelo menos a gente entende um pouco sobre essa questão da contribuição". Desse modo, os alunos respondem à questão que os motivou a estudar esse tema e deixam evidências que suas conjecturas acerca do tema sofreram alterações após a obtenção do problema que se propuseram a resolver. 


\section{Considerações Finais}

A análise dessa atividade de modelagem matemática, desenvolvida pelos alunos a partir de um tema proposto por eles, indica que os alunos foram autônomos na escolha do que analisar a respeito do tema - "Poupando a futura aposentadoria". Foram os conhecimentos de diversas naturezas mobilizados pelos alunos que desencadearam as discussões no grupo em relação ao que fazer para investigar tal tema ou avançar em sua investigação. É nesse 'o que fazer para' que signos foram utilizados e/ou produzidos pelos alunos.

Ao longo dessa atividade de modelagem matemática os alunos, na dinâmica de um grupo, se envolveram com um problema a investigar, com a busca por uma solução para ele e com a análise da resposta considerada por eles como solução para tal problema e, dessa forma, transitaram de uma situação inicial para uma final, comunicando seus conhecimentos, ora matemáticos, ora acerca da situação em estudo e, inclusive, conhecimentos articulados entre Matemática e situação por meio de signos, no sentido proposto por Peirce (2012), de que os signos representam algo que se quer comunicar. Tais signos retrataram, portanto, interpretações dos alunos em relação aos objetos/contextos de referência, a saber: tema em estudo, ao problema, objetos matemáticos vinculados ao problema e resposta aceita como solução para o problema.

Foram os conhecimentos mobilizados pelos alunos durante a atividade de modelagem matemática que determinaram os papéis desempenhados pelos signos. Esses papéis, associados às funções semiótica e epistemológica dos signos, possibilitaram que os alunos modificassem e atribuíssem novas interpretações aos signos utilizados e/ou produzidos por eles ao longo da atividade de modelagem matemática, a partir de relações que eles estabeleceram entre signo e objeto/contexto de referência.

De forma geral, os papéis desempenhados pelos signos determinaram as escolhas dessa ou daquela estratégia de encaminhamento dada à atividade de modelagem matemática e deixaram vir à tona tanto o processo de semiose, discutido por Peirce (2012), como a interdependência e reciprocidade entre signos e os que eles referenciam, discutida por Steinbring (2009) e, que nesta investigação, é abordada entre signo e contexto de referência. A cada escolha, novos signos foram produzidos em conexão com o contexto de referência e, reconhecidos os seus papéis, devido às funções semiótica e epistemológica desses signos, os alunos ratificavam, mudavam ou redirecionavam seus encaminhamentos para a atividade de modelagem matemática.

O conjunto de signos que conduziram o desenvolvimento da atividade apresentada e, consequentemente, a resolução do problema, sinaliza que o processo de geração de signos na mente do intérprete foi dinâmico e que decorreu do reconhecimento tanto do papel desempenhado por esses signos como do contexto de referência ao qual estavam associados. Ou seja, a cada papel desempenhado pelo signo, novos signos surgiam, constituindo-se uma trama semiótica. A interdependência e reciprocidade entre signos e 0 que eles referenciam, que aparece nesse contexto de trama, indica também a complementaridade entre eles. Tal complementaridade, contudo, decorre dos papéis desempenhados pelos signos, associados às suas funções semiótica e epistemológica. 


\section{Referências}

ALMEIDA, L. M. W. de. Um olhar semiótico sobre modelos e modelagem: metáforas como foco de análise. Zetetikè. FE - Unicamp. Campinas, v.18, número temático, p. 387-414, 2010.

ALMEIDA, L. M. W. de; SILVA, K. A. P. da; VERTUAN, R. E. Modelagem Matemática na Educação Básica. São Paulo: Contexto, 2012.

ALMEIDA, L. M. W. de; SILVA, K. A. P. da. Semiótica e as ações cognitivas dos alunos em atividades de Modelagem Matemática: um olhar sobre os modos de inferência. Ciência \& Educação. v.18, n.3, p. 623-642, 2012.

CARREIRA, S. Where there's a model, there's a metaphor: Metaphorical thinking in students' understanding of a mathematical model. Mathematical Thinking and Learning, v. 3, n.4, p. 261-287, 2001.

HOFFMANN, M. H. G. What is a "semiotic perspective", and what could it be? Some comments on the contributions to this special issue. Educational Studies in Mathematics, 61.Springer, pp. 279-291, 2006.

KEHLE, P.; CUNNINGHAM, D. J. Semiotic and Mathematical Modeling. In: International Journal of Applied Semiotics, v.3, n.1, p. 113-129, 2000.

KEHLE, P.; LESTER, F. K. Jr. A semiotic look at modeling behavior. In: LESH, R.; DOERR, H. M.; Beyond constructivism: Models and Modeling Perspectives on Mathematics Problem Solving, Learning and Teaching. Hillsdale, N.J.: Erlbaum, p. 97122, 2003.

NÖTH, W. Panorama da semiótica: de Platão a Peirce. 4. ed. São Paulo: Annablume, 2008.

OTTE, M. Mathematical epistemology from a semiotic point of view. In: PME International Conference, 25, Universityof Utrecht, The Netherlands, 2001.

PEIRCE, C. S. Semiótica e Filosofia: textos escolhidos. Tradução de Octanny Silveira da Mota e Leonidas Hegenberg. São Paulo: Cultrix, 1972.

PEIRCE, C. S. Semiótica. Tradução de José Teixeira Coelho Neto. 1. reimpr. da 4. ed. de 2010. v. 46. São Paulo: Perspectiva, 2012. (Estudos)

SANTAELLA, L. A teoria geral dos signos: como as linguagens significam as coisas. 4. reimpr. da 1. ed. de 2000. São Paulo: Cengage Learning, 2012.

SANTAELLA, L. Semiótica aplicada. São Paulo: Thomson Learning, 2007.

SEEGER, F. Beyond the Dichotomies - Semiotics in Mathematics Education Research. ZDM (Zentralblattür Didaktik der Mathematik) - The International Journal on Mathematics Education, Karlsruhe, v. 36, n. 6, pp. 206-216, 2004.

SILVA, K. A. P. da. Modelagem Matemática e Semiótica: algumas relações. Dissertação (Mestrado) - Pós-Graduação em Ensino de Ciências e Educação Matemática, Universidade Estadual de Londrina, Londrina, 2008. 
SILVA, K. A. P. da. Uma interpretação semiótica de atividades de Modelagem Matemática e Semiótica: implicações para a atribuição de significado. Tese (Doutorado) - Pós-Graduação em Ensino de Ciências e Educação Matemática, Universidade Estadual de Londrina, Londrina, 2013.

SILVA, K. A. P. da.; VERONEZ, M. R. D. Um olhar semiótico sobre a Modelagem Matemática. In: ALMEIDA, L. M. W. de; SILVA, K. A. P. da.(orgs.) Modelagem Matemática em Foco. Rio de Janeiro: Editora Ciência Moderna Ltda., p. 79-104, 2014.

STEINBRING, H. Basic Characteristics of Algebraic Thinking: Signs as Descriptors vs. Signs as Creators. CERME - Congress of the european society for research in mathematics education, 6, Proceedings...Institut Français de L'Éducation. Lyon: France, 2009.

STEINBRING, H. How do Mathematical Symbols Acquire their Meaning? In: Hans-Georg Weigand, Neville Neill, Andrea Peter-Koop, Kristina Reiss, Günter Törner, Bernd Wollring (Eds.): Developments in Mathematics Education in German-speaking Countries. Selected Papers from the Annual Conference of Didactics of Mathematics, Bern, 1999.Franzbecker: Hildesheim, S. pp. 113-123, 2002.

STEINBRING, $\mathrm{H}$. The construction of new mathematical knowledge in classroom interaction.An epistemological perspective. Mathematics Education Library, vol. 38, New York: Springer, 2005.

STEINBRING, $H$. What makes a sign a Mathematical Sign? an epistemological perspective on mathematical interaction. Educational Studies in Mathematics. Springer, v. 61 , p. 133-162, 2006.

VERONEZ, M. R. D. As funções dos signos em atividades de Modelagem Matemática. Tese (Doutorado) - Pós-Graduação em Ensino de Ciências e Educação Matemática, Universidade Estadual de Londrina, Londrina, 2013.

WILLIAMS, J.; WAKE, G. Metaphors and models in translation between college and wokplace Mathematics. Educational Studies in Mathematics. v. 64, p. 345-371, 2007.

Submissão: 14/12/2016

Aceite: 05/09/2017 